\title{
REFLECTION
}

\section{A Narrative Approach to Healing Chronic Illness}

\section{Thomas R. Egnew, EdD, LICSW}

Department of Family Medicine, University of Washington School of Medicine, Seattle, Washington
Conflict of interest: author reports none.

\section{CORRESPONDING AUTHOR}

Thomas R. Egnew, EdD, LICSW Department of Family Medicine University of Washington School of Medicine 1959 NE Pacific Street Seattle, WA 98195 tegnew@uw.edu

\section{ABSTRACT}

Many clinicians may feel poorly prepared to manage patient suffering resulting from the travails of chronic illness. This essay explores the thesis that chronically and terminally ill patients can be holistically healed by transcending the suffering occasioned by the degradations of their illnesses. Suffering is conveyed as a story and clinicians can encourage healing by co-constructing patients' illness stories. By addressing the inevitable existential conflicts uncovered in patients' narratives and helping them edit their stories to promote acceptance and meaning, suffering can be transcended. This requires that clinicians be skilled in narrative medicine and open to engaging the patient's existential concerns. By helping patients transcend their suffering, clinicians claim their heritage as healers.

Ann Fam Med 2018;16:160-165. https://doi.org/10.1370/afm.2182.

\section{EXPLORING SUFFERING}

$\mathrm{R}$ elieving suffering is the ancient goal, warrant for authority, test of adequacy, and ethical core of medicine. ${ }^{1}$ Fundamental to medicine's meaning and purpose, the relief of suffering should arguably be the foundation for medical decision making. Yet, modern medicine often fails to relieve suffering and, at times, can paradoxically exacerbate it through its curative focus, therapeutic activism, and a service delivery system poorly designed to meet the needs of chronically ill patients. ${ }^{2,3}$ In a robust quest to cure disease and extend life, attention to suffering has fallen by the wayside.

The contemporary discussion of suffering entered medical literature late in the 20th century. In 1982, Cassell explored suffering in an article in the New England Journal of Medicine. ${ }^{4}$ He later observed that, despite a widely referenced publication in an influential medical journal plus other articles and a book addressing the subject, ${ }^{5-7}$ little had changed in medicine's response to suffering. ${ }^{8}$ Cassell attributed this to beliefs that understanding and managing suffering is intuitive, and to the training and practice focus on disease management rather than on the ill person.

More recently, Epstein and Back noted that clinical care rarely addresses suffering and recommended 2 management approaches to relieve it. The first, diagnosing and treating disease to remove the source of suffering, remains paramount in medical efforts to alleviate suffering. The second, "turning toward" suffering, involves being open to the patient's experience so to enter the patient's world..$^{9(\mathrm{p} 2623)}$ By so doing, clinicians can help patients to refocus and reclaim important, meaningful, and generative aspects of their lives that foster growth through connection, transcendence, and healing. "Turning towards" broadens the focus of medical service delivery to include the patient's illness experience and suffering in management decisions. ${ }^{10}$

The travails of chronic illness exacerbate patient suffering. Given many clinicians may feel inadequately prepared to deal with the medical needs of chronically ill patients, ${ }^{11,12}$ it is likely even fewer feel prepared to help them relieve their suffering. ${ }^{13}$ Alleviating suffering requires that clinicians 
understand, identify, prevent, relieve, or manage it. ${ }^{14}$ Patients can be supported through the degradations of chronic and terminal illness by a thoughtful exploration of their suffering. Suffering is conveyed as a story which inevitably involves the existential aspects of a patient's life. Clinicians skilled in the nuances of narrative medicine can help patients edit their stories, which often involves engaging patients on levels relatively uninformed by medical education. Along the way, patients may be guided to find holistic healing.

\section{THE NATURE OF SUFFERING}

There is no commonly held definition of suffering. ${ }^{15,16}$ Cassell defined it as "the state of severe distress associated with events that threaten the intactness of the person."4(p640) Other definitions include: "an aversive emotional experience characterized by the perception of personal distress that is generated by adverse factors undermining the quality of life ${ }^{\prime \prime 17(p 57)}$; "an individual's experience of threat to self, a meaning given to events such as pain or loss ${ }^{118(\mathrm{p} 5)}$; "perceived damage to the integrity of the self"19(p2233); and "a syndrome of some duration, unique to the individual, involving a perceived relentless threat to one or more essential human values creating certain initially ominous beliefs and a range of related feelings". ${ }^{14(\mathrm{p} 11)}$ Taken together, one might conclude that suffering is personal and individual, is related to threats to the integrity of self, and is experienced by the whole person, not just the body.

There is greater consensus concerning the dynamics of suffering. Suffering involves "dissolution, alienation, loss of personal identity and/or a sense of meaninglessness." ${ }^{20(p 717)}$ While physical pain can cause suffering, suffering can arise separate from physical pain, and some people with pain do not particularly suffer because of it. ${ }^{4,19}$ Suffering ranges in intensity from distress ${ }^{4,14,18}$ to misery, anguish, and agony. ${ }^{14}$ It pertains to the meaning ascribed to events and inevitably entails existential and spiritual elements. ${ }^{16}$ "The more we suffer," maintained Elisabeth Kubler-Ross, "the earlier the spiritual quadrant opens and matures."21(p108) Such "deep suffering" is a transformative experience in which identity is challenged and changed to forever alter the life and relationships of the sufferer. ${ }^{16(\text { p23) }}$

Yet suffering remains an integral part of human experience, for life entails suffering-the first of Buddha's Four Noble Truths. We suffer when we don't have what we want or have what we don't want. ${ }^{22}$ Suffering prods us towards a more nuanced understanding of our place in the universe in the same way that physical pain warns us to avoid destructive activities. ${ }^{23}$ The individual, anecdotal nature of suffering, suffused with perception and meaning, is relayed as a narrative. ${ }^{24} \mathrm{To}$ understand the sufferer, one must understand the narrative, for it is through story that the patient's suffering is accessed. ${ }^{25}$ This means both hearing the illness story and listening for the suffering narrative therein.

\section{ILLNESS NARRATIVES AND SUFFERING}

Illness stories can take many forms-restitution, tragedy, quest, chaos. ${ }^{26}$ Restitution stories entail a recovery narrative, the happy-ending-triumph-over-adversitystory generally preferred in Western culture. ${ }^{27,28}$ In these narratives, transformations in the face of illness mirror the structure of mythic hero stories: separation from the world as known, isolation and change, and return to the world transformed to teach lessons of life renewed. ${ }^{29}$ The basic structure of illness stories involves the onset of, adjustment to, and struggle to incorporate illness into identity. ${ }^{30}$ "The experience of illness is always the experience of both 'having' and 'being had'," observed multiple sclerosis patient Kay Toombs. "I not only 'have' the illness, it also 'has' me." $31(\mathrm{p} 99)$

Other illness stories portend no happy ending. ${ }^{32}$ Stories of tragedy rescind possibilities for restitution; stories of quest present an unfolding metamorphosis with no end in sight; and stories of chaos depict a shattered, disorganized experience. Difficult to tell and hear, these tales reveal the embarrassment, shame, and guil $\mathrm{t}^{33}$ accompanying the radical loss of self-esteem wrought by disability. ${ }^{34,35}$ Central to the illness story is a threat to the assumption of personal indestructibility. ${ }^{31}$ These are tales that have been "wrecked," as the narrative of the present does not represent what the past was supposed to lead up to and the story of the future is fearful to behold..$^{27(\mathrm{p} 55)}$ "My history is no longer smooth and linear," wrote a paralyzed Robert Murphy, "but bisected and polarized. And my long-range future does not really exist." ${ }^{\prime 35(\mathrm{p} 26)}$

Some patients confront an inability to verbalize their experience. ${ }^{32}$ They may be rendered mute by their suffering ${ }^{36}$ unable to express their experience as they withdraw deeply into themselves. ${ }^{5}$ Others may struggle to find words to express their suffering. ${ }^{26}$ "Language supplies us with ways to express ever subtler levels of meaning," noted Lucy Grealy, disfigured by cancer of the jaw, "but does that imply language gives meaning, or robs us of it when we are at a loss to name things?" ${ }^{137(\mathrm{p} 44)}$ When voiced, telling the story of suffering helps a patient gain perspective, reconnect with the world, and forge a new identity. ${ }^{27}$

To determine if patients are suffering, we need to explore their experience. A number of questions have been found useful towards this end (Table 1). The goal is to engage the patient in a dialogue that kindles insights that cannot be individually attained. ${ }^{41}$ Promot- 
ing dialogue requires mutual respect, the ability to perceive the flow of meaning, the suspension of assumptions, and the skill to know what needs to be said when to help patients observe their thinking. ${ }^{42}$ Such interaction is crucial, for through dialogue patients can reflect on their stories and find their way to healing.

\section{WHAT IS HOLISTIC HEALING?}

A review of definitions of holistic healing reveals a variety of characteristics of the phenomenon. Healing involves cure or recovery from disease and the removal of impediments to and restoration of function. ${ }^{11,43,44}$ It engenders a sense of personal harmony, well-being, balance, and peace beyond bodily integrity. ${ }^{31,43}$ Healing accompanies the experience of transcending suffering ${ }^{42}$ which is perhaps the most inclusive of these characteristics. Transcending suffering arguably results in harmony, well-being, balance, and peace, but is independent of restoration of function and recovery from or cure of disease. It therefore remains a viable option for chronically and terminally ill patients. ${ }^{45,46}$ Indeed, preserving personal integrity, restoring well-being, maintaining function, and preventing and transcending suffering are the treatment goals for the chronically ill patient. $7,8,11,45,46$

Because illness begets suffering which is shared as a narrative of existential crisis, holistic healing involves addressing and resolving that existential predicament. ${ }^{46}$ "Existential" can relate to existence, the meaning of existence, or striving to find concrete personal meaning in existence. ${ }^{47(\mathrm{p} 100)}$ As serious illness thrusts patients into questions concerning the meaning of life, the

\section{Table 1. Questions to Explore Suffering}

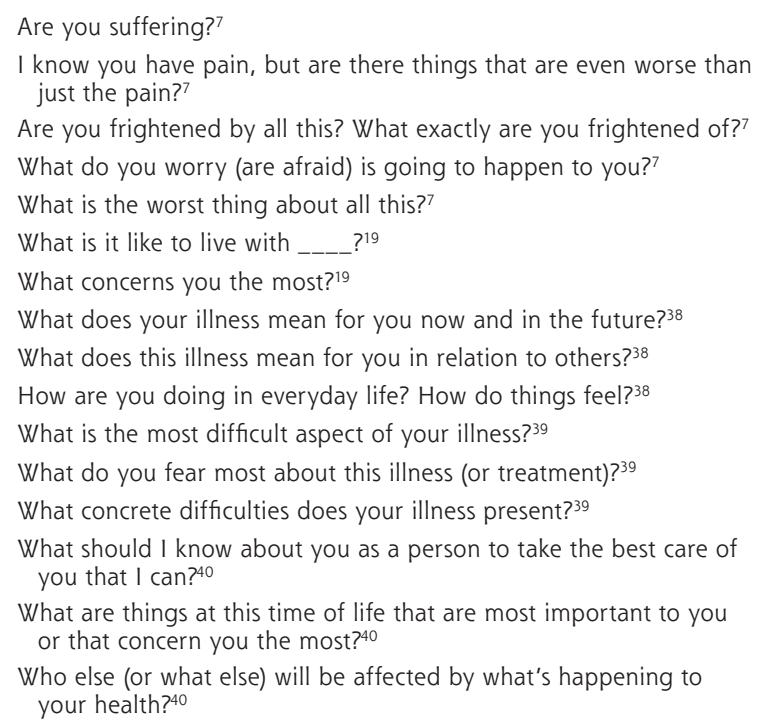

I know you have pain, but are there things that are even worse than just the pain? ${ }^{7}$

Are you frightened by all this? What exactly are you frightened of ?7 What do you worry (are afraid) is going to happen to you? ${ }^{7}$

What is the worst thing about all this? ${ }^{7}$

What is it like to live with ____ ? $^{19}$

What concerns you the most? ${ }^{19}$

What does your illness mean for you now and in the future? ${ }^{38}$

What does this illness mean for you in relation to others? ${ }^{38}$

How are you doing in everyday life? How do things feel? ${ }^{38}$

What is the most difficult aspect of your illness? ${ }^{39}$

What do you fear most about this illness (or treatment)? ${ }^{39}$

What concrete difficulties does your illness present? ${ }^{39}$

What should I know about you as a person to take the best care of you that I can? ${ }^{40}$

What are things at this time of life that are most important to you or that concern you the most? ${ }^{40}$

Who else (or what else) will be affected by what's happening to your health? ${ }^{40}$

holistic healer attends to the dynamics of existential disease just as biomedicine addresses the mechanics of physical disease. ${ }^{48}$ Existential predicaments commonly relate to death, gaining perspective on freedom, isolation, and meaninglessness ${ }^{49}$ and are reflected in the timeless themes associated with suffering.

Isolation, hopelessness, helplessness/vulnerability, and loss accompany a growing awareness of the disintegration of self, values and belief systems, and daily connections to the world. ${ }^{50}$ These themes may be discerned by the attentive listener of patients' stories and reflect the patients' sense of fragmented identity. At the least, the patient may share those aspects of life which can no longer be taken for granted. ${ }^{51}$ Fragmentation of identity is an opportunity to explore patients' suffering to affirm their experience, foster a therapeutic alliance, and establish a context from which their suffering may be transcended.

Suffering can be transcended through acceptance ${ }^{52,53}$ and investiture with meaning. ${ }^{54}$ Identity is formed through meaningful attachments to life. Severing or losing these attachments disrupts the sense of personal integrity and precipitates suffering. ${ }^{24,55}$ Accepting the change without pursuing reattachment or rejecting the loss can result in the transcendence of suffering. ${ }^{52,53}$ Palliative care specialist Ira Byock observed that sufferers found relief when they "surrendered who they were to a new reality of who they are." ${ }^{.56(\mathrm{p} 13)}$ Toombs would agree: "Achieving harmony in the face of illness means learning to live with bodily disorder as a permanent way of being." ${ }^{131(\mathrm{p} 102)}$ By relinquishing the desire for things to be different and accepting a new reality and identity, suffering can be transcended.

Suffering arises as a crisis of meaning, ${ }^{57}$ when previous meaning structures no longer apply to life $_{1}{ }^{17}$ and is transcended "the moment it finds a meaning." ${ }^{\text {"7 }}$ (p113) Meaning is "richly alive and powerful" and may be found in work or dedication to a cause, through love or relationships, or through the attitude one takes towards unavoidable suffering. ${ }^{47,58(\mathrm{p} 474) \text { "Whether }}$ (and in what way) illness causes suffering," Toombs asserted, "depends upon the whole texture of meanings and values intrinsic to a particular patient's unique life narrative..$^{1 / 4(\mathrm{p} 228)}$ Frankl maintained that meaning allows humans to endure and survive the direst situations. He fondly quoted Neitzsche: "He who has a why to live for can bear almost any how."47(p104) The patient with chronic illness inevitably confronts the question, "Why me?"35 Healers help patients find a "why" to transcend their suffering.

For McWhinney, healers recognize and acknowledge suffering, appreciate the meaning of the illness for the patient, are present when needed, and provide hope. "To be a healer," he noted, "is to help patients 
find their own way through the ordeal of their illness to a new wholeness." ${ }^{159(\mathrm{p} 95)}$ This requires compassion, conversation, and the ability to help patients find hope. ${ }^{20,38,60}$ Healers empathically witness suffering, compassionately engage patients, and possess proficiency in narrative medicine.

Narrative medicine is to the management of suffering as biomedicine is to the management of disease. It is medicine practiced with the narrative skills of "recognizing, absorbing, interpreting, and being moved by the stories of illness." ${ }^{\prime 61(\mathrm{p} 4)}$ Narrative competence entails knowing "what to do with stories." ${ }^{162(\mathrm{p} 1,265)}$ It begins by first listening for the story of suffering, a skill subtly more acute than listening to illness stories. ${ }^{63}$ Telling the story of suffering helps patients to reconstruct their painful past and gain distance on their suffering, receive affirmation of their search for a new identity, and find a language of interpretation that helps them transcend their suffering. ${ }^{39}$ Hearing and affirming a story of suffering aids holistic healing, and clinicians can play an important healing role by helping patients construct their illness narratives. ${ }^{64}$

Attentive listening discerns the form or general theme of the story, uncovers the sources of suffering therein, and hints at the possibilities for editing the story. In the process, a new understanding of self that reinstates or preserves personal integrity may be generated. ${ }^{53}$ Because suffering arises from a threat to the integrity of the intactness of an individual, the healing narrative is a story of fragmentation of identity, contemplation of ensuing suffering, and transcendence through acceptance and meaning. ${ }^{65}$

\section{A MATTER OF WORDS}

I have argued that suffering is managed by helping patients edit their illness stories to gain acceptance of and find meaning in their circumstances so to transcend their suffering. Thus, prostate cancer patient Anatole Broyard described doctors as storytellers who "can turn our lives into good or bad stories, regardless of the diagnosis" $66(\mathrm{p} 53)$ and avowed that "any meaning of illness is better than none. ${ }^{166(\mathrm{p} 65)}$ Yet, clinicians might resist this role, and the mention of suffering is rarely heard in clinical encounters. ${ }^{67}$ Principal barriers are training, temperament, and time.

Many clinicians may not feel prepared for such work. Medical training teaches little about suffering, ${ }^{9,13}$ devalues illness narratives ${ }^{68}$ promotes reifying patients' stories to medically pertinent facts ${ }_{1}{ }^{69}$ and guides clinical conversations through drop-down lists in an electronic medical record (EMR). There is no item for "suffering" on an EMR drop-down list. Moreover, the nature of suffering thwarts research paradigms valued by biomedicine, ${ }^{70}$ so no evidence-based guidelines exist for managing suffering. Suffering can arise from any aspect of a person's life, and clinicians may feel uncomfortable discussing non-biomedical issues. They may perceive that existential and metaphysical aspects of a patient's life are beyond their expertise, or simply do not see this as their role. Medical training focuses on the fixable, so clinicians may avoid problems for which they have no answer or cure.

Witnessing suffering can be painful. Some clinicians might fear a loss of emotional control ${ }^{71}$ that could compromise diagnostic clarity, or wish to avoid the "psychic numbness" that can accompany exposure to suffering. ${ }^{72(\mathrm{p} 51)}$ Clinicians must distinguish and cope with both their and their patient's feelings about the disease in the context of the patient's life, ${ }^{46,73}$ so as to not respond to their sense of helplessness with a hyperor hypo-engagement ${ }^{74}$ that impedes dialogue. But by engaging the patient in dialogue, the clinician can act as interpreter, arbiter, and advisor to enable patients to clarify their situations and make necessary decisions or adjustments. ${ }^{46}$ Interestingly, it is these non-technical, humanistic activities that some clinicians have found the most fulfilling and affirming of their work. ${ }^{74,54}$

Some clinicians may be concerned they do not have time to address suffering. But not all patients will be suffering, and unexpected psychosocial concerns emerge only every sixth to seventh consultation in primary care. ${ }^{76}$ When explored, conversations that satisfy patients last only 3 to 7 minutes. ${ }^{77} \mathrm{~A}$ longer dialogue suggests that the patient is struggling and needs re-appointment for further dialogue. More importantly, we remember critical events not sequentially but transformationally, defined by their life-changing nature. "Personal unity shatters vividly at the moment one receives a definitive diagnosis of incurable illness," observed Toombs. "In that instant, one recognizes that nothing will ever be (or can ever be) the same again." ${ }^{11(\mathrm{p} 99)}$ So also, healing can occur in an instant. "And then I experienced a moment of the freedom I'd been practicing for. ..." Grealy noted. "As a child, I had expected my liberation to come from getting a new face to put on, but now I saw it came from shedding something, shedding my image."137(p222) Through the power of continuity, a series of brief but connected dialogues can lead to profound transformation and healing.

Care must be taken to avoid imposing expectations for healing that lead vulnerable patients to feel they have failed for not obtaining a sense of transcendence. ${ }^{9}$ Since only the patient can find the acceptance or meaning in their illness story that leads to transcendence, the patient does the healing. The clinician helps by offering a relationship that encourages and affirms the search. "Healing is a gift," observed Dame 
Cicely Saunders, "and I don't think you are there to demand it. I think you do the caring that you can and you hope healing will come.".21(p101) The clinician-healer is less a problem-solver and more an accompanier on the healing journey. ${ }^{10}$

Any approach to healing that claims universal success should be held with suspicion. A narrative approach may well fail to bring relief to patients or families undergoing chaos and tragedy. Time and circumstance may not allow reconstruction of the patient's story to effect healing before calamity occurs. Catastrophic disease presentations such as a stroke that renders a patient comatose, can preclude dialogue. The chilling specter of cognitive decline foreshadowed in the word "dementia" warns both patient and clinician that time for editing illness stories is waning. In these cases, clinicians can encourage an active life review with an explicit effort to reconcile old wounds, suggest expressions of appreciation and affection, and actively engage the family to create positive memories. ${ }^{78} \mathrm{Con}$ fronting suffering that cannot be alleviated, clinicians can humbly and respectfully attempt to "soften" it. ${ }^{16(\mathrm{p} 3)}$

In the final analysis, what patients bring to their clinicians is their stories. When fortunate, these can be interpreted biomedically, and treatment leads to a cure, restoring health and potentially relieving suffering. But when patients become chronically or terminally ill, despite the best evidence-based approaches to managing their diseases, suffering is exacerbated and holistic healing becomes a treatment goal. Herein, clinicians can play instrumental roles by addressing the existential concerns of their patients and acting as guides who help them transcend suffering. ${ }^{79,80}$ In so doing, clinicians are never without something to offer their patients as they assume the mantle of their heritage as healers and connect with the meaning of their work.

To read or post commentaries in response to this article, see it online at http://www. AnnFamMed.org/content/16/2/160.

Key words: chronic disease; stress, psychological; suffering; physicianpatient relations

Submitted February 28, 2017; submitted, revised, July 28, 2017; accepted September 30, 2017.

\section{References}

1. Cassell EJ. The importance of understanding suffering for clinical ethics. J Clin Ethics. 1991;2(2):81-82.

2. Gawande A. Being Mortal: Medicine and What Matters in the End. New York, NY: Metropolitan Books; 2014.

3. Fox E. Predominance of the curative model of medical care. A residual problem. JAMA. 1997;278(9):761-763.

4. Cassel EJ. The nature of suffering and the goals of medicine. $N$ Engl J Med. 1982;306(11):639-645.

5. Cassell EJ. Recognizing suffering. Hastings Cent Rep. 1991;21(3):24-31.
6. Cassell EJ. The Nature of Suffering. New York, NY: Oxford University Press; 1991.

7. Cassell EJ. Diagnosing suffering: a perspective. Ann Intern Med. 1999;131(7):531-534.

8. Cassell EJ. The nature of suffering. Presented at: Grand Rounds at Dunedin School of Medicine; July 27, 1998; University of Otago, Dunedin, NZ.

9. Epstein RM, Back AL. A piece of my mind. Responding to suffering. JAMA. 2015;314(24):2623-2624.

10. Egnew TR. Suffering, meaning, and healing: challenges of contemporary medicine. Ann Fam Med. 2009;7(2):170-175.

11. Cassell EJ. The Nature of Healing. New York, NY: Oxford University Press; 2013.

12. Darer JD, Hwang W, Pham HH, Bass EB, Anderson G. More training needed in chronic care: a survey of US physicians. Acad Med. 2004; 79(6):541-548.

13. Egnew TR, Lewis PR, Myers KR, Phillips WR. Medical student perceptions of their education about suffering. Fam Med. 2017;49(6): 423-429.

14. Reed FC. Suffering and IIIness: Insights for Caregivers. Philadelphia, PA: F.A. Davis Company; 2003.

15. Wilkinson I. Suffering: A Sociological Introduction. Cambridge, UK: Polity Press; 2005.

16. Wright LM. Suffering and Spirituality: The Path to Illness Healing. Calgary, AB: 4th Floor Press; 2017.

17. Cherny NI, Coyle N, Foley KM. Suffering in the advanced cancer patient: a definition and taxonomy. J Palliat Care. 1994;10(2):57-70.

18. Kahn DL, Steeves RH. An understanding of suffering grounded in clinical practice and research, In: Ferrell BR, ed. Suffering. Sudbury, MA: Jones and Bartlett Publishers; 1995:3-27.

19. Chapman CR, Gavrin J. Suffering: the contributions of persistent pain. Lancet. 1999;353(9171):2233-2237.

20. Coulehan J. Suffering, hope, and healing. In: Moore RJ, ed. Handbook of Pain and Palliative Care: Biobehavioral Approaches for the Life Course. New York, NY: Springer; 2013:717-731.

21. Egnew TR. On Becoming a Healer [dissertation]. Seattle, Wash: Seattle University; 1994.

22. Dass R, Gorman P. How Can I Help? New York, NY: Alfred A. Knopf; 1985.

23. Gunderman RB. Is suffering the enemy? Hastings Cent Rep. 2002; 32(2):40-44.

24. Moerman DE. Physiology and symbols: the anthropological implications of the placebo effect. In: Romanucci-Ross L, Moerman D, Tancredi L, eds. The Anthropology of Medicine: From Culture to Method. South Hadley, MA: J. F. Bergin Publishers; 1983:156-167.

25. Kearney M. Mortally Wounded: Stories of Soul Pain, Death and Healing. Dublin: Marino Books; 1996.

26. Frank AW. Just listening: narrative and deep illness. Fam Syst Health. 1998;16:197-216.

27. Frank AW. The Wounded Storyteller: Body, Illness, and Ethics. Chicago, IL: University of Chicago Press; 1995.

28. Conway K. Illness and the Limits of Expression. Ann Arbor, MI: University of Michigan Press; 2007.

29. Campbell J. The Power of Myth. Flowers BS, ed. New York, NY: Anchor Books; 1991.

30. Kerr L. Always the same story: familiar narrative structures in Oliver Sacks and Nancy Mairs. Fam Med. 2010;42(2):97-99.

31. Toombs SK. Healing and incurable illness. Humane Med. 1995;11(3): 98-103.

32. Garden R. Telling stories about illness and disability: the limits and lessons of narrative. Perspect Biol Med. 2010;53(1):121-135. 
33. Lazare A. Shame and humiliation in the medical encounter. Arch Intern Med. 1987;147(9):1653-1658.

34. Price R. A Whole New Life. New York, NY: Scribner; 1994.

35. Murphy RF. The Body Silent. New York, NY: Norton; 1990.

36. Reich WT. Speaking of suffering: a moral account of compassion. Soundings. 1989;72(1):83-108.

37. Grealy L. Autobiography of a Face. New York, NY: Harper Perennial; 1995.

38. Sulmasy DP. The Healer's Calling: Spirituality for Physicians and Other Health Care Professionals. New York, NY: Paulist Press; 1997.

39. Younger JB. The alienation of the sufferer. ANS Adv Nurs Sci. 1995; 17(4):53-72.

40. Chochinov HM. Dignity and the essence of medicine: the $A, B, C$, and D of dignity conserving care. BMJ. 2007;335(7612):184-187.

41. Senge PM. The Fifth Discipline: The Art and Practice of the Learning Organization. New York: Doubleday/Currency; 1990.

42. Bohm D. The Special Theory of Relativity. New York, NY: W.A. Benjamin; 1965.

43. Hsu C, Phillips WR, Sherman KJ, Hawkes R, Cherkin DC. Healing in primary care: a vision shared by patients, physicians, nurses, and clinical staff. Ann Fam Med. 2008;6(4):307-314.

44. Scott JG, Cohen D, Dicicco-Bloom B, Miller WL, Stange KC, Crabtree BF. Understanding healing relationships in primary care. Ann Fam Med. 2008;6(4):315-322

45. Egnew TR. The meaning of healing: transcending suffering. Ann Fam Med. 2005;3(3):255-262.

46. Toombs SK. The metamorphosis: the nature of chronic illness and its challenge to medicine. J Med Humanit. 1993;14(4):223-230.

47. Frankl VE. Man's Search for Meaning. Boston, MA: Beacon Press; 2006.

48. Coulehan J. Compassionate solidarity: suffering, poetry, and medicine. Perspect Biol Med. 2009;52(4):585-603.

49. Yalom ID. Existential Psychotherapy. New York, NY: Basic Books; 1980.

50. Kearsley JH. Therapeutic use of self and the relief of suffering. Cancer Forum. 2010:34(2). http://www.cancerforum.org.au/issue/2010/ july/symptom-management-in-supportive-carel.

51. Baron RJ. An introduction to medical phenomenology: I can't hear you while I'm listening. Ann Intern Med. 1985;103(4):606-611.

52. Mikulas WL. Four noble truths of Buddhism related to behavior therapy. Psychol Rec. 1978;28(1):59-67.

53. Hayes SC, Smith S. Get Out of Your Mind and Into Your Life: The New Acceptance and Commitment Therapy. Oakland, CA: New Harbinger Publications; 2005

54. Farber SJ, Egnew TR, Herman-Bertsch JL, Taylor TR, Guldin GE. Issues in end-of-life care: patient, caregiver, and clinician perceptions. J Palliat Med. 2003:6(1):19-31.

55. Kegan R. The Evolving Self. Cambridge, MA: Harvard University Press; 1982.

56. Byock IR. When suffering persists.... J Palliat Care. 1994;10(2):8-13.

57. Barrett DA. Suffering and the process of transformation. J Pastoral Care. 1999;53(4):461-472.
58. Moerman DE, Jonas WB. Deconstructing the placebo effect and finding the meaning response. Ann Intern Med. 2002;136(6):471-476.

59. McWhinney IR. Illness, suffering and healing. In: A Textbook of Family Medicine. 2nd Edition. New York, NY: Oxford University Press; 1997: 83-103.

60. Mount BM, Boston PH, Cohen SR. Healing connections: on moving from suffering to a sense of well-being. J Pain Symptom Manage. 2007;33(4):372-388.

61. Charon R. Narrative Medicine: Honoring the Stories of Illness. New York, NY: Oxford University Press; 2006.

62. Charon R. What to do with stories: the sciences of narrative medicine. Can Fam Physician. 2007;53(8):1265-1267.

63. Welty E. One Writer's Beginnings. Cambridge, MA: Harvard University Press; 1998.

64. Brody H. "My story is broken; can you help me fix it?" Medical ethics and the joint construction of narrative. Lit Med. 1994;13(1):79-92.

65. Egnew TR. Meaning, medicine and healing. In: Russo-Netzer $P$ Schulenberg SE, Batthyány A, eds. Clinical Perspectives on Meaning. Zug, Switzerland: Springer; 2016: 299-321.

66. Broyard A. Intoxicated by My IIIness. New York, NY: Fawcett Columbine; 1992.

67. Lee TH. The word that shall not be spoken. N Engl J Med. 2013 369(19):1777-1779.

68. Kleinman A. The Illness Narratives. New York, NY: Basic Books; 1988.

69. Hunter KM. Doctors' Stories: The Narrative Structure of Medical Knowledge. Princeton, NJ: Princeton University Press; 1991.

70. Frank AW. Can we research suffering? Qual Health Res. 2001;11(3): 353-362.

71. Geller G. A "holistic" model of the healing relationship: what would that require of physicians? Am J Bioeth. 2006;6(2):82-85.

72. Nouwen HJM, McNeill DP, Morrison Da. Compassion. London, UK: Darton, Longman \& Todd; 2008

73. Shapiro J. Perspective: Does medical education promote professional alexithymia? A call for attending to the emotions of patients and self in medical training. Acad Med. 2011;86(3):326-332.

74. Back AL, Rushton CH, Kaszniak AW, Halifax JS. "Why are we doing this?": clinician helplessness in the face of suffering. J Palliat Med. 2015;18(1):26-30.

75. Horowitz CR, Suchman AL, Branch WT Jr, Frankel RM. What do doctors find meaningful about their work? Ann Intern Med. 2003; 138(9):772-775.

76. Peltenburg M, Fischer JE, Bahrs O, van Dulmen S, van den BrinkMuinen A. The unexpected in primary care: a multicenter study on the emergence of unvoiced patient agenda. Ann Fam Med. 2004; 2(6):534-540.

77. Branch WT, Malik TK. Using 'windows of opportunities' in brief interviews to understand patients' concerns. JAMA. 1993;269(13): 1667-1668.

78. Byock I. The Four Things That Matter Most. New York, NY: Simon \& Schuster; 2004.

79. Nuland S. How We Die. New York, NY: Knopf: 1994.

80. Farber SJ, Egnew TR, Herman-Bertsch JL. Defining effective clinician roles in end-of-life care. J Fam Pract. 2002;51(2):153-158. 